\title{
AS QUATRO ONDAS DO FEMINISMO: LUTAS E CONQUISTAS
}

\author{
Joasey Pollyanna Andrade da Silva* \\ Valter Moura do Carmo** \\ Giovana Benedita Jaber Rossini Ramos ${ }^{* * *}$
}

\section{RESUMO}

O presente artigo discute as quatros ondas importantes do feminismo, buscando demonstrar toda a trajetória, lutas, desafios e conquistas sob o aspecto do Direito Internacional dos Direitos Humanos. Foi utilizado o método dedutivo por meio de levantamento bibliográfico em livros e artigos científicos. O resultado do estudo demonstrou que, mesmo atualmente, as mulheres ainda permanecem em posição de inferioridade e desigualdade de gênero, sofrendo diversas violações de seus direitos, sendo necessária a adoção de medidas que trazem transformações sociais. Desse modo, a pesquisa visa contribuir para a ampliação do conhecimento acadêmico através dos pontos que foram abordados.

Palavras-chave: História do Feminismo; Movimentos Sociais; Gênero; Mulher; Política.

\section{THE FOUR WAVES OF FEMINISM: FIGHTS AND ACHIEVEMENTS}

\begin{abstract}
This article discusses the four important waves of feminism, seeking to demonstrate the entire trajectory, struggles, challenges and achievements under the aspect of international human rights law. The deductive method was used by means of bibliographic survey in books and scientific articles. The result of the study showed that, even today, women remain in a position of inferiority and gender inequality, suffering several violations of their rights, requiring the adoption of measures that bring social transformations. Thus, the research aims to contribute to the expansion of academic knowledge through the points that were addressed.
\end{abstract}

Keywords: History of Feminism; Social movements; Gender; Women; Politics.

\section{INTRODUÇÃO}

\footnotetext{
* Mestranda em Direito pela Universidade de Marília - UNIMAR, sendo bolsista PROSUP da CAPES. Graduada em Direito e em Enfermagem, ambos pela UNIMAR. Especialista em Gerontologia pela Universidade Estadual do Sudoeste da Bahia e em Saúde Pública pela Faculdade Internacional de Curitiba.

*** Possui graduação em Direito pela Universidade de Fortaleza - UNIFOR; mestrado em Direito Constitucional pela UNIFOR com período sanduíche na Universidade Federal de Santa Catarina - UFSC e doutorado em Direito pela UFSC, tendo realizado o doutorado sanduíche na Universidade de Zaragoza (Espanha) com bolsa do PDSE da CAPES e período de investigação na Universidade Federal da Paraíba - UFPB com bolsa do PROCAD da CAPES. Membro do Conselho Fiscal do CONPEDI.

*** Graduada em Direito pela Fundação de Ensino Eurípides Soares da Rocha. Mestre em Direito pela Universidade de Marília (2006). Aluna especial do Doutorado em Direito da Universidade de Marília UNIMAR. Docente no curso de Direito da UNIMAR. Coordenadora do Núcleo de Prática Jurídica (NPJ) do curso de Direito da UNIMAR.
} 
O movimento feminista surgiu a partir de reivindicações pelos direitos de liberdade e igualdade que, conquistados pelos homens do século XIX - advindos da Revolução Francesa por meio da Declaração de direitos do homem e do cidadão -, assegurava a eles vários direitos, e, desse momento em diante, começaram os questionamentos das mulheres sobre a igualdade de seus direitos.

A mulher era culturalmente, por uma visão patriarcal, confinada ao espaço privado, “do lar", submissa plenamente à figura masculina, quer fosse seu genitor ou companheiro; e quando casada, era tratada como mero objeto de procriação, considerada como propriedade dos homens, aos quais tinha o dever de obediência e subordinação. As mulheres eram oprimidas, escravizadas, exploradas, abusadas por homens que achavam possuir algum direito sobre a classe feminina. Por essa razão, as mulheres buscaram constantemente o seu direito de liberdade e de igualdade.

Não há motivos plausíveis para que mulheres, pobres, homossexuais, lésbicas, transexuais ou negros sofram qualquer tipo de discriminação, opressão, agressão, violência ou exploração. Como demonstrado na pesquisa, o processo de transformações culturais e sociais é letárgico e gradativo, uma vez que mudanças não acontecem sem que haja lutas, conflitos e divergência.

Um ponto observado na pesquisa é que, desde a Revolução francesa até os dias atuais, ainda persistem situações de opressão, discriminação, preconceito, desigualdade, exploração e de injustiça difundida por todo o mundo.

Nesse seguimento, a pesquisa teve como finalidade demonstrar a trajetória, lutas, desafios e conquistas do movimento feminista sob o aspecto do Direito Internacional dos Direitos Humanos e de várias conquistas ainda necessárias. Pode-se observar que mesmo com toda a evolução dos tempos modernos, a mulher ainda sofre preconceito, perseguições, discriminação, explorações, desigualdades salariais e outras desvantagens em relação ao homem.

Sob a óptica desse cenário, a sociedade machista e patriarcal precisa de muito tempo para entender e transformar as suas concepções, devendo se pautar na construção de uma ideologia de que os seres humanos não podem ser separados, desprezados, inferiorizados e 
julgados por questões de raça, gênero, credo e opção sexual; as diferenças devem ser respeitadas.

Cada onda feminista analisada permitiu identificar que as mulheres foram conquistando lentamente o seu espaço e foi possível reconhecer alguns sinais de mudança, como a mulher inserida na política, no mercado de trabalho, ocupando cargos e funções exclusivos dos homens.

Não obstante, mesmo com os avanços tecnológicos, a disseminação das informações por meio da internet, de redes sociais de comunicação reconhece que a luta realizada pelo movimento feminista em prol da igualdade de direitos ainda está longe de ser concretizada.

Portanto, a pesquisa visa analisar, criticamente, o movimento feminista por meio da análise das ondas do feminismo, e quais as transformações ocorridas no contexto social. Para responder a esse questionamento, buscou-se evidenciar as lutas e trajetórias de mulheres no decorrer da história, em busca de condições de igualdade, realidade observada ainda nos dias atuais. Por isso, faz-se relevante demonstrar os impactos reais do movimento feminista para que se possa contribuir nas transformações sociais e culturais da sociedade.

A partir desse questionamento proposto como problema, a pesquisa consiste no desenvolvimento de uma pesquisa de natureza qualitativa, que visa proporcionar maior interação com o problema e construir critérios, envolvendo uma revisão bibliográfica, documental, abordando o contexto histórico, demonstrando as lutas, trajetórias e conquistas do movimento feminista, aplicando o método dedutivo, com intuito de demonstrar a necessidade da ampliação de conhecimento acerca do movimento feminista, suas ideias e reivindicações para que possam ser conhecidas e levadas à frente nas lutas sociais, buscando os seus direitos garantidos por lei, para que ocorram mudança e conscientização sobre o conceito de mulher na sociedade.

\section{EVOLUÇÃO HISTÓRICA}

A partir do século XIX, iniciaram-se, de forma significativa, as primeiras reivindicações das mulheres tanto nos Estados Unidos como na Europa. Não obstante, houve reivindicações anteriores a esse período realizadas por mulheres e/ou por todas as pessoas que se sentiam oprimidas, injustiçadas; em algum momento elas buscam os seus direitos por meio dessas reivindicações. Porém, foi nessa época que as mulheres começaram a despertar, a se 
movimentar naturalmente conservando no seu interior um ritmo de fluxo e refluxo comparado às ondas, que por um momento foram imperceptíveis representando a calmaria, isto é, a submissão das mulheres, quando de repente as ondas vieram fortes e poderosas, como demostrado nas lutas e conquistas do movimento feminista (SIQUEIRA; BUSSINGUER, 2020).

Esses momentos são considerados grandiosos, conforme menciona Mariana Coelho (2002, p. 44): "quero sugerir a existência de pelo menos quatro momentos áureos na história do feminismo". Tais momentos são revelados sobre um contexto histórico através de quatros ondas importantes do feminismo.

\section{A PRIMEIRA ONDA}

A primeira onda ocorre no século XIX e tem como pauta principal a busca das mulheres pelos direitos para alcançar igualdade com os homens, acreditando que iriam atingir essa finalidade por meio da educação e de uma relação mais simétrica dentro do casamento. Esse tipo de direito e de reivindicações começou a ser tratado desde o Renascimento; logo, com a chegada da Modernidade, iniciou-se um movimento reivindicatório com constantes mudanças no paradigma de pensamento, no qual as mulheres começaram a apresentar ideias diferentes no contexto educacional, social e político, direitos reservados somente ao sexo masculino (DUARTE, 2003).

Durante o Iluminismo, formou-se um pensamento burguês trazendo um discurso de igualdade, contraindo o discurso de superioridade imposto pela nobreza. Então, foi a partir da Revolução Francesa que as mulheres abriram o conceito de "sujeitos iguais" através de ideias filosóficas de igualdade, de liberdade e de fraternidade, que inspiraram as mulheres a refletir sobre as suas próprias condições dentro da sociedade. Com isso, as mulheres participaram ativamente da Revolução Francesa na linha de frente, contribuindo com o pensamento Iluminista (SIQUEIRA; BUSSINGUER, 2020).

No entanto, depois da Revolução Francesa, os direitos foram conquistados pelos homens, quando ocorreu uma mudança no status do cidadão, que passou a ser considerado um sujeito de direitos, sobretudo sobre a propriedade, sendo a principal a ideia do liberalismo, trazida pelo filósofo inglês John Locke, que seria justamente o ideal de igualdade, liberdade, o 
direito do próprio corpo e da própria vida. No entanto, mesmo as mulheres participando ativamente, lado a lado, com os homens na Revolução Francesa, não eram consideradas sujeitos de direitos (SIQUEIRA; BUSSINGUER, 2020).

Após a Revolução Francesa, foi criado um documento denominado direitos do homem e do cidadão em que as mulheres não estão inclusas, contendo apenas direitos garantidos aos homens e cidadãos, como aludem os Artigos $1^{\circ}$ e $2^{\circ}$ da Declaração de direitos do homem e do cidadão - 1789 .

Art.1 ${ }^{\mathbf{0}}$. Os homens nascem e são livres e iguais em direitos. As distinções sociais só podem fundamentar-se na utilidade comum.

Art. $2^{\mathbf{0}}$. A finalidade de toda associação política é a conservação dos direitos naturais e imprescritíveis do homem. Esses direitos são a liberdade, a propriedade a segurança e a resistência à opressão. (USP, 1978).

Logo, as mulheres que participaram intelectualmente e ativamente da revolução, passaram a reivindicar os mesmos direitos conferidos aos homens.

Neste contexto é valido citar os nomes de duas grandes pensadoras que participaram intelectualmente desse período da Revolução. Na França, Olympe de Gouges ${ }^{\dagger}$; e na Inglaterra, Mary Wollstonecraft. Olympe de Gouges era escritora francesa, autora de um documento considerado o texto fundante do feminismo, denominado "Direitos da Mulher e da Cidadã", em oposição ao documento dos homens, essa escritora tenta argumentar de várias formas, com a finalidade de convencer os leitores de que as mulheres teriam de usufruir os iguais direitos concedidos aos homens (DUARTE, 2003).

Já Mary Wollstonecraft", escritora inglesa da época, conhecida por "Uma Reivindicação pelos Direitos da Mulher”, obra literária escrita 1792, considerada uma das escritas mais importantes, pois trata de uma sociedade que adota desigualdades e discriminação de gênero na esfera política, social, econômica e de educação. No entanto, a

\footnotetext{
${ }^{\dagger}$ Defensora da democracia e dos direitos das mulheres. Na sua obra Declaração dos Direitos da Mulher e da Cidadã, de setembro de 1791, opôs-se ao patriarcado de época e ao modo pelo qual a relação entre homem e mulher se expressava na Declaração dos Direitos do Homem e do Cidadão, durante a Revolução Francesa. Devido aos seus escritos e atitudes pioneiras, foi guilhotinada.

* Escritora, filósofa, e defensora dos direitos da mulher, inglesa. Atualmente, é considerada como uma das fundadoras da filosofia feminista, tanto a sua vida como as suas obras exercem influências importantes no movimento feminista.
} 
escrita dessas brilhantes pensadoras não se constituiu de grande relevância, não conquistando nenhum tipo de direito a partir dessas obras (ESTACHESKI; MEDEIROS, 2017).

Somente no século seguinte as mulheres resolveram se organizar e fazer um movimento feminista conhecido como movimento das suffragettes, ou movimento das sufragistas. As mulheres se organizam e montam estratégias em busca dos seus direitos, porém sem muitos resultados. O máximo que elas conseguiram foi serem ridicularizadas pelos homens, nos jornais e propagandas. Sem a compreensão da população machista, e sem ser ouvidas, as mulheres tornaram o movimento mais intenso, quebrando algumas propriedades e fazendo greves de fome (PINTO, 2010),

A partir dessa conduta, o movimento feminista ganhou um pouco mais de visibilidade, ainda que de forma negativa, pois trouxe algumas reflexões do pensamento masculino, se as mulheres estão reivindicando é porque esses direitos fazem sentido, são importantes para esse grupo. Por outro lado, as mulheres que ficaram inertes ao movimento começaram a pensar e a argumentar que também possuíam tais direitos. Ao adotar essas estratégias, as mulheres aos poucos começaram a caminhar nas conquistas desses direitos (PINTO, 2010).

Na mesma época, nos Estados Unidos, houve um movimento das mulheres em busca da igualdade dos direitos, principalmente do voto. Essas mulheres se uniram com os homens que lutavam contra a abolição da escravatura, ao mesmo tempo existia o combate à escravidão e o esforço pela conquista de seus direitos. Porém, o movimento abolicionista alcançou mais sucesso do que o movimento das mulheres (WEBER, 1964).

Durante essa época, uma abolicionista e ex-escravizada, Sojourner Truth, fez um discurso que se tornou inesquecível para a história, sobre a confluência entre o sufrágio feminino e os direitos dos negros. Desse modo, começou a fazer toda a diferença dentro das reflexões do movimento feminista da primeira onda, ao repetir diversas vezes, "Eu não sou mulher":

E não sou mulher? Olhem pra mim! Olhem pro meu braço! Tenho arado e plantado, e juntado em celeiros, e nenhum homem poderia me liderar! E não sou uma mulher? Posso trabalhar tanto quanto e comer tanto quanto um homem - quando consigo o que comer - e aguentar o chicote também! E não sou uma mulher? Dei à luz treze filhos, e vi a grande maioria ser vendida para a escravidão, e quando eu chorei com minha dor de mãe, ninguém, a não ser Jesus me ouviu! E não sou mulher? 
Se a primeira mulher feita por Deus teve força bastante para virar o mundo de ponta-cabeça sozinha, estas mulheres juntas serão capazes de colocá-lo na posição certa novamente! E agora que elas estão querendo fazê-lo, é melhor que os homens permitam. (SANTOS; AZEVEDO, 2020, p. 24).

Após o discurso da Sojourner Truth, as mulheres começaram a refletir, primeiro sobre os paradoxos masculinos da visão de considerá-las um sexo frágil, em seguida as mulheres negras observaram tratamento inferior e diferenciado em relação às mulheres brancas (SANTOS; AZEVEDO, 2020).

Esse movimento da primeira onda era realizado por mulheres brancas que tinham a finalidade de adquirir direitos iguais aos homens, como aprender a ler e a escrever, porque compreendiam que a suposta inferioridade se dava devido à educação ser diferente em relação aos homens; e também, em sua maioria, refutavam o casamento, enxergando dentro dele relações bastante assimétricas; devido à submissão imposta pela sociedade machista, eram abusadas sexualmente, criando uma concepção de casamento como uma forma de prostituição legal, ou de escravidão sexual, pois os homens teriam uma mulher à disposição para servi-los em todos os aspectos, inclusive sexualmente. Então, seriam essas as três reivindicações: educação, casamento e direitos iguais, almejavam ser iguais perante as leis (SIQUEIRA; BUSSINGUER, 2020).

Nesse seguimento, a autora Nísia Floresta (1989, p. 35), em sua obra Direitos das mulheres e injustiça dos homens, corrobora com a ideia de que os homens se beneficiam oprimindo as mulheres e somente o conhecimento através da educação permitiria às mulheres a percepção de sua condição subalternidade quando menciona:

Se cada homem, em particular, fosse obrigado a declarar o que sente a respeito de nosso sexo, encontraríamos todos de acordo em dizer que nós nascemos para seu uso, que não somos próprias senão para procriar e nutrir nossos filhos na infância, reger uma casa, servir, obedecer e aprazer aos nossos amos, isto é, a eles homens. Tudo isto é admirável e mesmo um mulçumano não poderá avançar mais no meio de um serralho de escravas.

Contudo, se de um lado essas demandas representavam problemas das mulheres da classe média e da elite, por outro lado existiam as mulheres trabalhadoras, proletárias, que tinham outras demandas, como desigualdades salariais, que ocorriam normalmente dentro das indústrias. Essas mulheres formaram outro tipo de movimento, relacionado ao socialismo, o movimento operário. Destaca-se Flora Tristan relacionada ao socialismo tópico, o movimento anarquista traz Ema Goldman, e como feminista marxista temos Clara Zetkin e Alexandra 
Kollontai. Esses nomes foram de extrema importância para o feminismo operário (CAMPOI, 2011).

\section{SEGUNDA ONDA}

A segunda onda feminista ocorre em 1960 e vai até 1980. Direitos foram conquistados na maior parte dos países, mas as mulheres eram iguais aos homens perante a lei apenas no papel, pois na prática essas igualdades não ocorriam. Então, esse movimento se preocupa em compreender por que ainda existe submissão das mulheres, será que elas seriam naturalmente inferiores aos homens e por isso não alcançavam na prática essa igualdade? Com isso, começa-se a questionar a ideia de mulher, de feminilidade. O que significa ser mulher? Surgem então as três pensadoras: Simone de Beauvoir, Carol Hanisch, e Betty Fridman (CAMPOI, 2011).

Simone de Beauvoir era uma filósofa francesa, autora de uma grande obra que trouxe reflexões para o movimento feminista, cujo nome é "O Segundo Sexo", que traz justamente esse questionamento: o que é ser mulher? Existiria uma essência feminina? E por que o mundo se constitui pelo egocentrismo, ou seja, por meio de uma perspectiva masculina e de opressão? (DUARTE, 2006).

Betty Friedan era uma americana que vivia nos Estados Unidos nas décadas de 60 e 70, autora da obra A mística feminina, que se tornou best seller, em que era possível perceber que, nessa época, os americanos rotulavam a figura feminina como cuidadora do lar ou dona de casa. A partir das vivências que a autora tinha como dona de casa, surgem alguns questionamentos de como seria esse tipo de mulher que os Estados Unidos estavam idealizando como essência feminina, como mulher americana. Demonstrando uma visão patriarcal em inserir as mulheres apenas na vida privada, tirando-as da vida pública, mesmo após a conquista desses direitos, principalmente depois da segunda guerra (DUARTE, 2006).

Outra importante ativista do movimento feminista que trouxe várias questões foi a americana Carol Hanisch. No período de 60 e 70, nos Estados Unidos, aconteceram vários movimentos sejam hippies, contra a guerra do Vietnã e pacifista. Hanisch traz a frase "O pessoal é político" com grandes reflexões, porque essas mulheres se reúnem e se expõem cada veze mais, relatando fatos sobre a sua vida como forma de desabafo, começam a falar das opressões vivenciadas dentro de suas próprias residências. Salientando que o problema de 
opressão não poderia ser visto apenas como um problema privado, mas, sim, como um problema de interesse público, ou seja, deveria mudar a estrutura pública em relação à estrutura privada, para que relações de violência que as mulheres sofrem em sua vida privada também sejam transformadas (SARDENBERG, 2018, p.16).

Surge, a partir desses eventos históricos, a expansão do feminismo pelo mundo, por meio de movimentos sociais, trazendo uma nova concepção de mulher reflexiva, buscando seus direitos e valores, negados por um modelo tradicional de ideias machistas. Devido a essa nova reestruturação, o ano 1970 tornou-se relevantes para o movimento feminista internacional. Já 1975 foi marcado pela Primeira Conferência Mundial sobre as Mulheres, na Cidade do México, estruturada pela Organização das Nações Unidas (ONU), onde foi declarado o Ano Internacional das Mulheres, fortalecendo as lutas das mulheres feministas (SARDENBERG, 2018).

Logo, houve a organização de dois eventos importantes: o primeiro foi o Movimento Feminino pela Anistia (MFPA), que tinha como uma articuladora a ex-prisioneira política Therezinha Zerbini, que levantou um manifesto nacional. A ideia principal era conscientizar as organizações civis e entidades de classe sobre a concessão da anistia aos presos exilados e políticos (VARGAS, 2005).

O segundo movimento foi constituído por grupos privados e informais de feministas apoiadas pela Organização das Nações Unidas (ONU), que trouxe o fortalecimento de novas ideias e concepções, surgindo novos movimentos associados às lutas sindicais, defendendo melhores condições de trabalho, salário digno, medidas de saúde e segurança, associações profissionais, partidos políticos, obtendo autonomia em relação aos seus direitos, defrontando os abusos e discriminações sofridas pela questão de gênero, enfrentando a política vigente (OTTO, 2004).

Houve então o período da pós-ditadura militar, que se destacou pelas lutas sociais, concedendo a oportunidade de requerer os seus direitos, despertando uma visão democrática, marcada pela redemocratização, pelos movimentos feministas sociais, adquirindo um cenário com condutas mais reivindicatórias, obtendo apoio internacional, que impôs ao Estado implementar políticas públicas mais eficazes, produzido vínculo com as organizações feministas não governamentais (OTTO, 2004). 
Marcado pela redemocratização, o ano de 1980 fomentou a elaboração de novos grupos feministas, como a formação do grupo das acadêmicas. Devido às agressões e violências praticadas contra as mulheres, foram criadas, no ano de 1985, as primeiras delegacias femininas, com a finalidade de proteger esse grupo de mulheres em condições de vulnerabilidade, vítimas de diversas formas de violências e agressividades dos companheiros (OTTO, 2004).

Nesse seguimento, uma das conquistas que merece destaque dentro desse processo de democratização foi o controle sobre a fecundidade através da anticoncepção, no qual as mulheres defendiam a autonomia na escolha dos seus destinos relacionados à reprodução e controle do seu corpo. Nesse contexto de saúde integral da mulher, o governo brasileiro fomentou a questão de planejamento familiar convocando o Ministério da Saúde (MS), que apresentou a proposta do Programa de Assistência Integral à Saúde da Mulher (PAISM), que abrangia todas as peculiaridades relacionadas à saúde da mulher de forma integral, em todos os níveis de saúde, e não apenas questões sobre concepção e contracepção (COSTA; GUILHEM; SILVER, 2006).

O direito ao planejamento familiar está consagrado na Constituição Federal de 1988 em seu $\S 7^{\circ}$ do Art. $226 \mathrm{CF} / 88$ :

$\S 7^{\circ}$ Fundado nos princípios da dignidade da pessoa humana e da paternidade responsável, o planejamento familiar é livre decisão do casal, competindo ao Estado propiciar recursos educacionais e científicos para o exercício desse direito, vedada qualquer forma coercitiva por parte de instituições oficiais ou privadas. (BRASIL,1988).

Esse direito da mulher foi regulamentado pela Lei ${ }^{\circ}$ 9263, de 12 de janeiro de 1996, em que o Ministério da Saúde ratifica a liberdade e autonomia da escolha dos seus métodos contraceptivos durante o programa de planejamento familiar do SUS:

Planejamento familiar é o direito que toda pessoa tem à informação, à assistência especializada e ao acesso aos recursos que permitam optar livre e conscientemente por ter ou não ter filhos. O número, o espaçamento entre eles e a escolha do método anticoncepcional mais adequado são opções que toda mulher deve ter o direito de escolher deforma livre e por meio da informação, sem discriminação, coerção ou violência. (BRASIL, 1996).

Segundo os autores Corrêa e Ávila (2003, p. 20), a "saúde integral da mulher" surgiu em um contexto de saúde através de propostas políticas e debates públicos, que 
resultaram na implementação do Programa de Assistência Integral à Saúde da Mulher (PAISM), em que as feministas levantavam a bandeira na defesa do direito sobre o seu próprio corpo com a aludida frase "nosso corpo nos pertence", reivindicando ao Estado ações resolutivas sobre as seguintes demandas: a legalização do aborto, o acesso aos métodos contraceptivos inclusive os de infertilidades, garantindo durante a gravidez assistência ao prénatal e parto humanizado, bem como ampliação da relação entre médico e usuária por meio de todas as informações pertinentes à saúde da mulher. (CORRÊA; ÁVILA, 2003).

Dessa forma, o movimento feminista conquistou os direitos sobre o seu corpo, fortalecendo valores através de lutas constantes que ensejaram em discussão e ampliação desse tema, desenvolvendo outras políticas públicas como sexualidade feminina, violência contra a mulher, direitos reprodutivos, programa de combate ao Câncer de mama e colo de útero entre outros. Houve sim uma evolução de concepção e valores que eram discriminados, marginalizados e proibidos (SILVA, 2008).

No período de 1980-1982 ocorreu uma ampliação do movimento feminista em relação às mulheres inseridas em campos políticos, fazendo parte do eleitorado feminino, integrando em programas e plataformas eleitorais. Surgindo assim, os Departamentos Femininos com organização partidária, admitindo as mulheres em legendas partidárias como foi no caso da vitória do Partido do Movimento Democrático Brasileiro (PMDB) para governar São Paulo, que assegurou a criação do Conselho Estadual da Condição Feminina, esse ponto foi considerado o terceiro momento do feminismo (COSTA, 2005).

\section{TERCEIRA ONDA}

Surge na época de 1990, trazendo as diversidades feminina, com demandas específicas, trazendo com bastante força do movimento negro, movimentos homossexuais, lesbianismo, transexuais entre outros.

Em 1993, as Conferências Mundiais, em especial a Conferência de Direitos Humanos, e em 1994 a Conferência de População e Desenvolvimento, trouxeram a viabilidade de inúmeros canais de informações e troca de experiência. E a partir da IV Conferência Mundial da Mulher e pela Comissão Interamericana de Direitos Humanos e a Convenção Interamericana trouxe como pauta questões como prevenção, punição e 
erradicação da violência contra a mulher, sendo esses eventos resultantes de lutas, com manifestações e atuações femininas, que garantiu as alterações no Código Penal. Devido a essas conquistas, surge uma nova visão da sexualidade com a autonomia, liberdade e valorização da mulher, mitigando dessa forma as relações de desigualdade entre os gêneros (MIRANDA, 2015).

Nesse seguimento, observa-se um grande avanço nas conquistas femininas, como a vinculação da mulher na Justiça, em 2002, que trouxe a instituição da Secretaria de Estado dos Direitos da Mulher, e em 2003 a Secretaria Especial de Políticas para as Mulheres trazendo como principais finalidades as articulações de políticas públicas voltadas para o atendimento de todas as mulheres (MIRANDA, 2015).

Assim sendo, a ampliação do status sobre o feminismo brasileiro foi intensificado a partir dos avanços na política, desafiando tabus e paradigmas, em que a mulher estava ocupando cargos que anteriormente eram exclusivos aos homens. Desse modo, a mulher ingressou na política, conquistou espaços em ministérios, diretorias, gerência, coordenadorias secretarias e outros. Simultaneamente, esse grupo de mulheres monitora, pressiona, propõe e reivindica a efetiva atuação do Estado, para o cumprimento de todas as suas demandas de forma efetiva. A I Conferência Nacional de Políticas para Mulheres expressou a força desse movimento através mobilizações e de articulações de novas alianças, por meio de propostas inovadoras, englobando o desafio para a igualdade numa perspectiva de gênero (OTTO, 2004).

$\mathrm{Na}$ atual conjuntura, as mulheres alcançaram a liberdade de expressão do pensamento, seu direito a voto, seu engajamento na política, assumindo cargos elevados na esfera do legislativo, judiciário e executivo, trabalhando ativamente em construções, como motoristas, arquitetas entre outras, ocupando diversos cargos e funções. Outro destaque foi o direito sobre o seu próprio corpo, a sua sexualidade o direito de decidir sobre a contracepção, esterilização, abortos previstos em lei e opção sexual. Foi através de um longo percurso, enfrentando diversas formas de discriminações, segregação, violência, na maioria das vezes inferiorizadas por uma sociedade machista, que esse movimento conquistou força e ganhou o seu espaço ao longo dos anos. 


\section{QUARTA ONDA?}

Surgiu a partir de 2010, ainda não há um consenso sobre a existência da quarta onda nos estudos mais tradicionais, mas se torna nítido o seu surgimento, motivado pelo ativismo virtual ou o chamado ciberativismo, além disso traz um diversidade de feminismos, também o ingresso da interseccionalidade e a mobilização de coletivos, grupos de pessoas que se movimentam, para fazerem manifestações, esses coletivos são organizações mais fluídas, diferentes das organizações tradicionais, esses grupos se reúnem através das redes sociais, assim o pessoal vai se engajando para determinada ação (CASTRO, 2020).

O primeiro aspeto que será abordado a respeito dessa onda será a atuação nos meios digitais. Atualmente, não se pode negar a importância das novas tecnologias como forma de comunicação virtual, que possibilitou um ativismo digital ou ciberativismo, também conhecido como ciberfeminismo, quando este for relacionado ao movimento feminista na internet (PEREZ; RICOLDI, 2019).

Dessa forma, alude Ana Cláudia Leal Felgueiras (2017, p. 119) a respeito ciberfeminsmo, em que as “jovens militantes que foram criadas já na era digital e que compreendem o alcance desta ferramenta de comunicação e sabem muito bem como utilizála”. Portanto, a internet cria o ciberfeminsmo.

Portanto, redes sociais, facebook, WhatsApp, Instagram, blogs, sites, youtube e outros são meios de informação e comunicação via internet, através desses aplicativos e sites permite-se a disseminação de informações sobre as causas feministas, alcançando inúmeros públicos. Com isso, possibilitou-se expandir as ideologias feministas como a defesa dos direitos de igualdade através de discursos virtuais, empoderando cada vez as mulheres, propiciando um novo mecanismo de fala. Além de facilitar a ampliação de informações em grande escala de idealizações feministas, o mundo digital proporcionou a mobilização política das mulheres, que por meio das redes sociais são organizadas ações, reuniões, manifestações, protestos e divulgação dos resultados (PEREZ; RICOLDI, 2019).

O segundo aspecto será a interseccionalidade, definida por Kimberle Crenshaw (2002, p. 177):

A interseccionalidade é uma conceituação do problema que busca capturar as consequências estruturais e dinâmicas da interação entre dois ou mais 
eixos da subordinação. Ela trata especificamente da forma pela qual o racismo, o patriarcalismo, a opressão de classe e outros sistemas discriminatórios criam desigualdades básicas que estruturam as posições relativas de mulheres, raças, etnias, classes e outras.

A chamada interseccionalidade pretende denunciar um montante de formas de opressão, trazendo a discussão sobre em que momento essas formas de opressão e submissão convergem. A ideia central é uma busca por uma liberdade integral, ou seja, a libertação dos preconceitos, das correntes opressoras de raça, gênero, classe e por extensão do próprio sistema capitalista, a quarta onda pretende uma luta conjunta contra todas essas formas de opressão, trazendo a diversidade do feminismo. Assim, alude Silva e Pedro (2016, p. 194): "Diferentemente das ondas que a antecederam, a proposta mais ousada de uma quarta onda do feminismo [...] é reconhecida pela incorporação dos diversos feminismos de correntes horizontais, como o negro, lésbico e o masculino e os LGBT” (PEREZ; RICOLDI, 2019).

Com o mundo digital, essas ações interseccionais são difundidas, alcançando um maior número de pessoas, transmitindo conhecimento sobre as suas intervenções no combate ao racismo, homofobia, lesbofobia e LGBTfobia. Com a democratização das informações transmitidas pela internet, possibilitou-se o recebimento denúncias de casos de preconceitos de diversas formas, trazendo novas lutas para as feministas (PEREZ; RICOLDI, 2019).

O terceiro aspecto dessa onda são as organizações fluídas, coletivos femininos, estão distantes de ações financiadas pelo Estado. Para Gretha Leite Maia (2013, p. 69), esse coletivo "pode agregar múltiplas demandas, e, por meio de debates periódicos, são definidas quais as pautas prioritárias, a partir da conjuntura política que é mantida em permanente análise".

A maioria dos coletivos femininos são formados por acadêmicos que promovem discussões, debates sobre questões de gênero, raça e sexualidade dentro da universidade. Com a ampliação do ensino superior, através da implementação de cotas raciais, possibilitou-se o ingresso dos alunos menos favorecidos e negros na universidade (SARMENTO; REIS; MENDONÇA, 2017).

Em contrapartida, em 2003, com a gestão do governo Lula, foi fortalecida a participação de mulheres e LGBT's no campo político. A partir desse fortalecimento, houve 
uma maior atuação, com intensa mobilização de mulheres, negros e LGBT's, nas lutas pela igualdade de direitos (CASTRO, 2020).

Em 2013, houve grande manifestação trazida pela tão conhecida Jornadas de Junho de 2013. Foram Protestos e Engajamento Político ocorridos nos municípios de São Paulo e de Belo Horizonte, o que marcou o início de um novo ciclo de protestos coletivos que almejava à luta antirracista, classista e em favor de direitos da população LGBT, em que tais divulgações dos eventos foram criadas e difundidas por meio das redes digitais de comunicação, o que permitiu a ampliação das manifestações na rua (SARMENTO; REIS; MENDONÇA, 2017).

Alguns estudiosos consideram o marco inicial no Brasil da quarta onda com a Marcha das Vadias, que ocorreu na Cidade de São Paulo em 2011, porém esse evento começou no Canadá, observando-se aqui a repercussão do feminismo de modo global.

Já na atual política, o presidente Jair Bolsonaro demonstra um retrocesso do governo brasileiro nos direitos humanos, com relação aos direitos das mulheres na saúde sexual e reprodutiva, ao apresentar uma contraproposta às temáticas das declarações internacionais sobre direitos humanos e igualdade de gênero exposta no dia internacional da mulher, em que o país brasileiro se negou a assinar a declaração do Conselho de Direitos Humanos das Nações Unidas (ONU). O texto assegurava direito de meninas e mulheres ao acesso a direitos reprodutivos e sexuais. No atual quadro de vulnerabilidade, esse documento foi assinado conjuntamente por mais de 60 países na cidade de Genebra (CHADE, 2019).

As principais pautas rejeitadas pelo governo brasileiro foram devido ao texto trazer ambiguidade ao fazer referência aos direitos sexuais e reprodutivos e igualdade de gênero, explicando que no Brasil existem apenas direitos reprodutivos, e solicitando a modificação da palavra gênero para "igualdade entre homens e mulheres", além de outros pedidos para retirar os seguintes trechos do texto das resoluções como "serviços de saúde sexual e reprodutiva", "desigualdades com base em gênero" e "vulnerabilidade à violência sexual" (CUNHA, 2020).

Os representantes do governo brasileiro, ao fazerem tais indagações, a declaração Conselho de Direitos Humanos exprime negligência e violações aos direitos humanos das mulheres, pelo reconhecimento da luta por igualdade e inclusão, adotando claramente uma política patriarcal voltada para um marco social desigualitário, onde se desassociam os corpos 
femininos e masculinos, trazendo uma radical separação entre mulheres e homens, impondo padrões de condutas distintas, em relação às funções sociais e laborais. Com essa postura antipolítica de gênero, gera ainda mais consequências entre desigualdades salariais e sociais, aumentando os números de assédios e agressões sexuais, violência doméstica e feminicídios, sendo este último agravado pela atual política de flexibilização do porte e posse da arma de fogo (CUNHA, 2020).

Outro ponto da pauta discordado pelo governo brasileiro foi em trechos do texto que mencionavam a necessidade de garantir acesso a pessoa vítimas de crises humanitárias para serviços de "saúde sexual e saúde reprodutiva" e a uma outra referência à necessidade de que as organizações humanitárias da ONU garantam serviços básicos para populações afetadas, entre eles serviços para assegurar "saúde sexual e saúde reprodutiva", justificando que tais trechos do documento não coadunam com diferentes situações e prioridades políticas e legislativas de cada estado, além propiciar abertura para a prática do aborto (CHADE, 2019).

O governo brasileiro adota posicionamento que restringe a prática de aborto mesmo nos casos previstos em leis, como trazido nos termos dos direitos do nascituro, defendendo o direito à vida desde a concepção, defendendo uma política conservadora contra o aborto e em defesa da família baseada em casais heterossexuais (CUNHA, 2020).

Como visto na portaria $\mathrm{n}^{\mathrm{o}} 2.282$, de 27 de agosto de 2020 no seu artigo $1^{\circ}$ que diz:

Art. $1^{\circ}$ É obrigatória a notificação à autoridade policial pelo médico, demais profissionais de saúde ou responsáveis pelo estabelecimento de saúde que acolheram a paciente dos casos em que houver indícios ou confirmação do crime de estupro. (MINISTÉRIO DA SAÚDE, 2020).

Mediante essa portaria, consta-se como uma forma de restrição através da obrigatoriedade de os profissionais de saúde notificarem a autoridade policial, no caso de aborto legal a pessoa vítima de estupro, desencorajando o acesso aos serviços de saúde, não respeitando o direito de privacidade após ter sofrido violência sexual. Desse modo, as mulheres e meninas podem recorrer a abortos ilegais, arriscando as suas vidas e saúde, aumentando assim o índice de mortalidade e morbidade maternas no país (CUNHA, 2020).

Atualmente, o Brasil não está respeitando o que está previsto no artigo 96 da Declaração e Plataforma de Ação de Pequim (ONU, 1995, p. 179): 
Os direitos humanos das mulheres incluem os seus direitos a ter controle sobre as questões relativas à sua sexualidade, inclusive sua saúde sexual e reprodutiva, e a decidir livremente a respeito dessas questões, livres de coerção, discriminação e violência. A igualdade entre mulheres e homens no tocante às relações sexuais e à reprodução, inclusive o pleno respeito à integridade da pessoa humana, exige o respeito mútuo, o consentimento e a responsabilidade comum pelo comportamento sexual e suas consequências.

Infelizmente as políticas consagradas pelo governo Bolsonaro demonstram graves violações aos direitos humanos em relação aos direitos das mulheres.

\section{CONSIDERAÇÕES FINAIS}

Este trabalho demonstrou algumas vertentes do feminismo trazido pelas 04 (quatro) ondas feministas. No tocante à primeira onda, as mulheres almejavam exercer a sua cidadania através do sufrágio, e derrubar os óbices legais a igualdade de gênero, isto é, o feminismo liberal. Essa onda ocorreu durante a Revolução Francesa, trazendo ideais liberais, que se perpetuam até a atual época, em que as mulheres não pretendem ser superiores aos homens, apenas querem ter os mesmos direitos conferidos a esse gênero como respeito, as mesmas condições de trabalho e a mesma igualdade salarial.

A segunda onda demonstrou o feminismo radical e a sua expansão pelo mundo através de movimentos sociais. Apresenta a mulher vítima de opressão sofrida por seu companheiro, trazendo uma nova concepção de mulher reflexiva, que busca os seus direitos e valores que lhes foram negados por um modelo tradicional de ideias machistas.

Já na terceira, em que houve a diversidade feminina, enfatizando as demandas sobre a força do movimento negro, movimentos homossexuais, lesbianismo, transexuais. Outro ponto foi o engajamento da mulher na política e a sua atuação em inúmeras áreas profissionais que eram conferidas exclusivamente aos homens.

Por último, a quarta onda trouxe o ciberfeminismo, a diversidade de feminismo, o ingresso da interseccionalidade e a mobilização de coletivos. Com a disseminação das informações, promoveu estratégias através das redes sociais, transmitindo conhecimento sobre as suas intervenções no combate ao racismo, homofobia, lesbofobia e LGBTfobia. Demostrando também as violações do atual governo a direitos humanos relacionados a mulheres, como direitos sexuais e reprodutivos com garantia ao acesso universal e igualitário, 
no entanto as atitudes demonstram uma política patriarcal, conservadora voltada para um marco social desigualitário, retrocedendo em políticas públicas que buscam assegurar os direitos das mulheres.

Apesar de todas as conquistas e lutas travadas pelo feminismo dos últimos séculos, ainda no atual momento as mulheres enfrentam resistências políticas, patriarcais e culturais, além de desigualdades de gênero, são vítimas de violência, na maioria das vezes são assassinadas por companheiros ou ex-companheiros, desenvolvem atividades na sua própria residência e as que exercem atividades fora, são minoria em cargos de direção, gerência, coordenação e liderança, ganhando salários inferiores aos dos homens na mesma função. Em sua maior parte, sofrem assédio sexual desde a adolescência, em casa, na rua, no ônibus, na escola e no trabalho.

Não obstante, a sociedade impõe uma estrutura social de gêneros, diferenciando os papéis entre homens e mulheres estabelecendo atividades peculiares, em que o papel feminino precisa ser valorizado e não inferiorizado. Na visão patriarcal, muitos homens trazem a concepção de mulher como objeto sexual, símbolo de desejo e poder, exposto pela própria mídia e redes sociais. Por outro lado, a sociedade impõe padrões de beleza, exibindo corpos esculturais, com roupas sensuais, visto em propagandas de carros, cervejas, programas de TVs, danças como axé, funk, pagode, samba, entre outros, em que associa o poder de masculinidade adquirindo várias mulheres. Assim sendo, verificam-se diversas formas de abusos sexuais, estupros por motivos torpe, desconstruindo os valores dados à sexualidade, sendo notada como forma demonizada, reprodutiva, explorada e usada contra as próprias mulheres. Muitas das vezes as mulheres sofrem assédio sexual no trabalho quer seja doméstico, intelectual ou técnico, diversos tipos de discriminações, preconceitos, desvalorização, ridicularização, superexploração e são mal remuneradas.

A essência do feminismo não se caracteriza em substituir os papéis com os homens ou ter domínio sobre o gênero masculino, mas sim em defender os direitos das mulheres e combater as desigualdades de gênero. Por essa razão, os movimentos sociais resultaram em grandes conflitos, pois tinham a finalidade de ratificar o processo de emancipação e de libertação das mulheres, por isso são muito estigmatizados.

A luta é incessante em busca da igualdade de gênero, que consiste em processo longo, árduo e contínuo, não corresponde à substituição de posição social ou superioridade 
das mulheres e sim garantias de igualdade sem qualquer forma de discriminação e violência de gênero espécie, raça ou sexo. Portanto, foi de grande relevância a pesquisa, porém há uma necessidade de dar continuidade ao estudo dos direitos e conquistas das mulheres, visto que, a análise realizada não conseguiu esgotar o tema devido a sua multidimensionalidade, que sempre traz questões inovadoras sobre o feminismo para serem discutidas, estratégias e difusão feminista, bem como as dificuldades enfrentadas e desafios e resistências constantes.

\section{REFERÊNCIAS}

BRASIL. [Constituição (1988)]. Constituição da República Federativa do Brasil de 1988. Brasília, DF: Presidência da República, 2021. Disponível em:

http://www.planalto.gov.br/ccivil_03/constituicao/constituicao.htm. Acesso em: 5 mar. 2021.

BRASIL. Lei n⿳ 9.263, de 12 de janeiro de 1996. Regula o $§ 7^{\circ}$ do artigo 226 da Constituição Federal, que trata do planejamento familiar, estabelece penalidades e dá outras providências. Disponível em:

https://www.camara.leg.br/proposicoesWeb/prop_mostrarintegra;jsessionid=12181 A6865861 3ECA9C9DA6751866E77. proposicoesWebExterno2? codteor=306441\&filename=Legislacao Citada+-PL+5230/2005. Acesso em: 01 abr. 2021.

CAMPOI, Isabela Candeloro. O livro "Direitos das mulheres e injustiça dos homens" de Nísia Floresta: literatura, mulheres e o Brasil do século XIX. História, Franca, v. 30, n. 2, p. 196213, dez. 2011. DOI: https://doi.org/10.1590/S0101-90742011000200010. Disponível em: https://www.scielo.br/scielo.php?script=sci_arttext\&pid=S0101-90742011000200010. Acesso em: 31 mar. 2021.

CASTRO, Priscila Rodrigues de. As lutas feministas e sua articulação pelas mídias digitais: percepções críticas. Rev. Katálysis, Florianópolis, v. 23, n. 3, p. 459-469, set./dez. 2020. DOI: https://doi.org/10.1590/1982-02592020v23n3p459. Disponível em: https://www.scielo.br/scielo.php?script=sci_arttext\&pid=S141449802020000300459\&lng=pt\&nrm=iso\&tlng=pt. Acesso em: 01 abr. 2021.

CHADE, Jamil. Brasil se abstém em voto sobre saúde sexual e reprodutiva na ONU. Blog de Jamil Chade, 26 jun. 2019. Disponível em:

https://jamilchade.blogosfera.uol.com.br/2019/06/26/brasil-se-abstem-em-voto-sobre-saudesexual-e-reprodutiva-na-onu/. Acesso em: 14 abr. 2021.

COELHO, Mariana. A evolução do feminismo: subsídios para sua história. 2. ed. Curitiba: Imprensa Oficial do Paraná, 2002.

CORRÊA, S.; ÁVILA, M.B. Direitos sexuais e reprodutivos: pauta global e percursos brasileiros. In: BERQUÓ, E. (org.). Sexo e vida: panorama da saúde reprodutiva no Brasil. Campinas: UNICAMP, 2003. p. 17-78.

COSTA, Ana Alice Alcantara. O movimento feminista no Brasil: Dinâmicas de uma intervenção política. Revista Gênero, RJ/Niterói, v. 5, n. 2, p. 9-35, 2005. Disponível em: https://periodicos.uff.br/revistagenero/article/view/31137. Acesso em: 02 abr. 2021. 
COSTA, Ana Maria; GUILHEM, Dirce; SILVER, Lynn Dee. Planejamento familiar: a autonomia das mulheres sob questão. Rev. Bras. Saúde Mater. Infant. v. 6, n. 1, p. 75-84, mar. 2006. DOI: https://doi.org/10.1590/S1519-38292006000100009. Disponível em: https://www.scielo.br/scielo.php?pid=S1519-

38292006000100009\&script=sci_abstract\&tlng=pt. Acesso em: 01 abr. 2021.

CRENSHAW, Kimberle. Documento para o encontro de especialistas em aspectos da discriminação racial relativos ao gênero. Rev. Estud. Fem., Florianópolis, v. 10, n. 1, p. 171 188, 2002. Disponível em: https://www.scielo.br/pdf/ref/v10n1/11636.pdf. Acesso em: 10 mar. 2021.

CUNHA, Leonam Lucas Nogueira. A antipolítica de gênero no governo Bolsonaro e suas dinâmicas de violência. Revista de Estudios Brasileños, Salamanca, v. 7, n. 14, p. 49-61, 2020. Disponível em: https://www.revistas.usp.br/reb/article/view/176467/163971. Acesso em: 13 abr. 2021.

DUARTE, Constância Lima. Feminismo e literatura no Brasil. Estud. av., São Paulo, v. 17, n. 49, p. 151-172, set./dez. 2003. DOI: https://doi.org/10.1590/S0103-

40142003000300010. Disponível em:

https://www.scielo.br/scielo.php?script=sci_arttext\&pid=S0103-40142003000300010. Acesso em: 01 abr. 2021.

DUARTE, Ana Rita Fonteles. Betty Friedan: morre a feminista que estremeceu a América.

Rev. Estud. Fem., Florianópolis, v. 14, n.1, p. 287-293, jan./abr. 2006. DOI:

https://doi.org/10.1590/S0104-026X2006000100015. Disponível em:

https://www.scielo.br/scielo.php?script=sci_arttext\&pid=S0104-026X2006000100015.

Acesso em: 31 mar. 2021.

ESTACHESKI, Dulceli de Lourdes Tonet; MEDEIROS, Talita Gonçalves de. A atualidade da obra de Mary Wollstonecraft. Rev. Estud. Fem., Florianópolis, v. 25, n. 1, p. 375-378, jan./abr. 2017. DOI: https://doi.org/10.1590/1806-9584.2017v25n1p375. Disponível em: https://www.scielo.br/scielo.php?script=sci_arttext\&pid=S0104-

026X2017000100375\#: :text=A\%20atualidade\%20da\%20obra\%20\%C3\%A9,do\%20Minist \%C3\%A9rio\%20das\%20Mulheres\%2C\%20da. Acesso em: 30 mar. 2021.

FELGUEIRAS, Ana M. Cláudia Leal. Breve Panorama Histórico do Movimento Feminista Brasileiro: das Sufragistas ao Ciberfeminismo, Revista Digital Simonsen, n. 6, p. 108-121, maio 2017. Disponível em: http://www.simonsen.br/revista-digital/wpcontent/uploads/2017/05/montagem-da-revista-Reparado111.pdf. Acesso em: 10 mar. 2021.

FLORESTA, Nísia. Direitos das mulheres e injustiça dos homens. São Paulo: Cortez, 1989.

MAIA, Gretha Leite. A juventude e os Coletivos: como se articulam novas formas de expressão política. Revista Eletrônica do Curso de Direito da UFSM, Santa Maria, v.8, n.1, p. 58-73, 2013. DOI: https://doi.org/10.5902/198136948630. Disponível em:

https://periodicos.ufsm.br/revistadireito/article/view/8630. Acesso em: 10 mar. 2021.

MINISTÉRIO DA SAÚDE. Portaria no 2.282, de 27 de agosto de 2020. Dispõe sobre o Procedimento de Justificação e Autorização da Interrupção da Gravidez nos casos previstos em lei, no âmbito do Sistema Único de Saúde-SUS. Disponível em:

http://bvsms.saude.gov.br/bvs/saudelegis/gm/2020/prt2282_28_08_2020.html. Acesso em: 10 abr. 2021. 
MIRANDA, Cynthia Mara. Os movimentos feministas e a construção de espaços institucionais para a garantia dos direitos das mulheres no Brasil e no Canadá. Interfaces Brasil/Canadá: Revista Brasileira de Estudos Canadenses, Canoas, v. 15, n. 1, p. 347-385, 2015. Disponível em:

https://periodicos.ufpel.edu.br/ojs2/index.php/interfaces/article/view/6721. Acesso em: 01 abr. 2021.

PEREZ, Olívia Cristina; RICOLDI, Arlene Martinez. A quarta onda feminista: interseccional, digital e coletiva. In: Congresso Latino-americano de Ciência Política (ALACIP), 10, Monterrey, Nuevo León, México, 2019. Anais [...]. s. 1.: ALACIP; Asociación Mexicana de Ciencias Políticas A.C. (AMECIP); Tecnológico de Monterrey, 2019. Disponível em: https://alacip.org/cong19/25-perez-19.pdf. Acesso em: 02 abr. 2021.

PINTO, Céli Regina Jardim. Feminismo, história e poder. Rev. Sociol. Polit., Curitiba, v. 18, n. 36, p. 15-23, jun. 2010. Disponível em:

https://www.scielo.br/scielo.php?script=sci_arttext\&pid=S0104-

44782010000200003\#: :text=Palavras\%2Dchave\%3A\%20movimento\%20feminista\%3B,\%3 B\%20poder\%3B\%20mulheres\%20e\%20pol\%C3\%ADtica. Acesso em: 01 abr. 2021.

\section{ONU. Declaração e Plataforma de Ação da IV Conferência Mundial Sobre a Mulher.}

Pequim 1995. Disponível em: https://www.onumulheres.org.br/wpcontent/uploads/2013/03/declaracao_beijing.pdf. Acesso: 14 abr. 2021.

OTTO, Claricia. O feminismo no Brasil: suas múltiplas faces. Estudos Feministas, Florianópolis, v. 12, n. 2, p. 238-241, maio/ago. 2004. Disponível em: http://www.scielo.br/scielo.php?script=sci_arttext\&pid=S0104-026X2004000200015. Acesso em: 30 mar. 2020.

SARMENTO, Rayza; REIS' Stephanie; MENDONÇA, Ricardo Fabrino. As Jornadas de Junho no Brasil e a questão de gênero: as idas e vindas das lutas por justiça. Rev. Bras.

Ciênc. Polít., Brasília, n. 22, p. 93-128, jan./abr. 2017. Disponível em:

https://www.scielo.br/scielo.php?script=sci_arttext\&pid=S0103-33522017000100093. Acesso em: 02 abr. 2021.

SANTOS, Kelly Cristine Martins dos; AZEVEDO, Nadia Pereira da Silva Gonçalves. Análise discursiva da posição sujeito das mulheres negras militantes reverberada pelo discurso de Sojourner Truth. Policromias - Revista de Estudos do Discurso, Imagem e Som, Rio de Janeiro, v. 5, n. 2, p. 11-35, maio/ago. 2020. Disponível em:

https://revistas.ufrj.br/index.php/policromias/article/view/33589. Acesso em: 01 abr. 2021.

SILVA, Elizabete Rodrigues da. Feminismo radical - pensamento e movimento. Revista Travessias - Educação, Cultura, Linguagem e Arte, v. 2, n. 3, p. 1-14, 2008. Disponível em: http://e-revista.unioeste.br/index.php/travessias/article/view/3107. Acesso em: 01 abr. 2021.

SIQUEIRA, Carolina Bastos de; BUSSINGUER, Elda Coelho de Azevedo. As ondas do feminismo e seu impacto no mercado de trabalho da mulher. Revista Thesis Juris-RTJ, São Paulo, v. 9, n. 1, p. 145-166, jan./jun. 2020. Disponível em:

http://www.revistagenero.uff.br/index.php/revistagenero/article/viewFile/380/285. Acesso em: 31 mar. 2021.

USP. Universidade de São Paulo. Declaração de direitos do homem e do cidadão - 1789. Disponível em: http://www.direitoshumanos.usp.br/index.php/Documentos-anteriores- 
\%C3\%A0-cria\%C3\%A7\%C3\% A3o-da-Sociedade-das-Na\%C3\%A7\%C3\%B5es-at\%C3\%A91919/declaracao-de-direitos-do-homem-e-do-cidadao-1789.html. Acesso em: 30 mar. 2021.

VARGAS, Mariluci Cardoso de. O Movimento Feminino pela Anistia como partida para a redemocratização brasileira. In: Encontro Estadual de História, 9, 2008, Porto Alegre.

Vestígios do Passado: a história e suas fontes. Porto Alegre: ANPUH/RS, 2008. Disponível em: http://eeh2008.anpuh-

rs.org.br/resources/content/anais/1212369464_ARQUIVO_trabalhocompletoanpuh.pdf.

Acesso em: 29 mar. 2021.

WEBER, Max. Economia e Sociedade. México: Fondo de Cultura Económica, 1964.

WOLLSTONECRAFT, Mary. Reivindicação dos direitos da mulher. São Paulo: Boitempo, 2016. 